\title{
Studying the effect of fire retardant coating on the fire hazard characteristics of wood using infrared thermography
}

\author{
Denis Kasymov ${ }^{1, *}$ and Mikhail Agafontsev ${ }^{1}$ \\ ${ }^{1}$ National Research Tomsk State University, 36 Lenin Ave., Tomsk, 634050, Russia
}

\begin{abstract}
This paper represents a study concerning the effect of fire retardant treatment «FUKAM» on the fire hazard characteristics of pine, aspen and larch. The front of model ground fire was investigated to estimate its effect on the surface of wood samples. Infrared thermography was used as a diagnostic method. The surface temperature distribution was obtained for the test wood samples after exposure to a fire front that was modeled using pine needles. The probability of ignition was estimated for the chosen experimental parameters for each kind of wood. The fire hazard characteristics of wood after fire retardant treatment showed a significant reduction in the surface temperature and the resistance to fire for the chosen parameters of the experiment compared to the same untreated samples.
\end{abstract}

\section{Introduction}

Wildfires cause significant material and economic damage to the territories. Numerous theoretical [1-3] and experimental investigations [4-7] conducted to study the effect of fires do not explain the mechanism of fire transition to the wooden constructions, their ignition and subsequent combustion.

The development of chemical industry led to the development of means such as fire retardants which prevent partially or completely the ignition of treated surfaces. On the market there are a lot of such means which have the different technical parameters and a different degree of toxicity.

The literature provides a huge amount of theoretical and experimental data on the fire hazard properties of wood [8], the study of burning particles acting on wooden constructions [9-11], and the effect of intense heating through thermal radiation [4,12-13]. It is of interest to study the effect of fire retardants on the fire hazard properties of wood exposed to combustion under laboratory conditions.

In this work the effect of fire front on the surface of wood samples was studied to estimate the effect of fire retardant treatment «FUKAM» [14]. Infrared thermography was used as a diagnostic method. The main advantage of this method is the high spatial and temporal resolution of measurements [15].

\footnotetext{
* Corresponding author: denkasymov@gmail.com
} 


\section{Laboratory equipment and methodology of the experiment}

In the infrared region the sample surface characteristics were recorded using a thermal imager JADE J530SB with a 2.5-2.7 micron optical filter that allowed a temperature to be measured in the range of 500-850 K. In order to record a temperature in the range of 293 $550 \mathrm{~K}$, the recording was conducted without a filter.

The frame frequency was 50 frames/sec. The moisture content of the samples was controlled using a moisture analyzer AND MX-50 with an accuracy of $0.01 \%$, and the mass of the samples was controlled using an electronic balance AND HL-100.

Combustion, simulated by forest fuel (FF), consisted of pine needles (Pinus Pinaster) and represented a site with a width that was close to the size of the wood sample. The samples of pine, aspen and larch were used as the samples which imitated the wood used in constructions. The dimensions of the samples in the experiment were $(\mathrm{L} \times \mathrm{W} \times \mathrm{H})$ : $0.23 \times 0.02 \times 0.1 \mathrm{~m}$ for pine, $0.17 \times 0.02 \times 0.1 \mathrm{~m}$ for aspen, and $0.16 \times 0.02 \times 0.12 \mathrm{~m}$ for larch. The liquid means «FUKAM» was used as a fire-bio wood protection applied to sawn, dressed and log building elements for housing, public, industrial and agricultural purposes [14].

Consumption of the means «FUKAM» that provides the fire retardant properties was approximately $400 \mathrm{~g} / \mathrm{m}^{2}$, which corresponds to the II group of fire retardant resistance. The dipping method was used as a technique of wood treatment.

The wood samples were placed in the sealed plastic containers filled with the «FUKAM» means, so that the wood was completely covered with liquid. The samples were in the containers for 2-3 hours and then removed, giving the unabsorbed solution to flow down. The samples were placed in a force-draft oven FDO-0.5 - 200 with a temperature of $70^{\circ} \mathrm{C}$ for 12 hours until complete drying.

Fig. 1 shows a scheme of the experiment:


Fig. 1. Experimental setup. 1 - site with FF, 2 - wood sample, 3 - thermal imager JADE J530SB.

During the experiments, the moisture content of the samples was $5.55 \%$ for pine, $5.83 \%$ for aspen, $3.76 \%$ for larch, and $8.03 \%$ for pine needles. The FF mass maintained constant and was $50 \mathrm{~g}$ in the experiment, thus modeling a ground fire of weak intensity. The model of a ground forest fire of low intensity was used, since this fire was the most widespread in the natural environment, the modeling of which under laboratory conditions did not require significant maintenance costs.

The experiment was conducted as follows. The FF site 1 was located in front of the sample and ignited by a linear source located under the site. The produced fire front acted upon the wood sample 2 that was vertically fixed. The sample surface was recorded using a thermal imager 3. The experiment was conducted in two stages. At the first stage, the wood samples were studied without fire retardant treatment. At the second stage, the samples were covered with a fire-retardant coating. A series of three repetitions were conducted for each stage. The processing of data was carried out using the Altair software. 


\section{Results}

The surface temperature distribution was obtained for the test wood samples (Fig. 2).

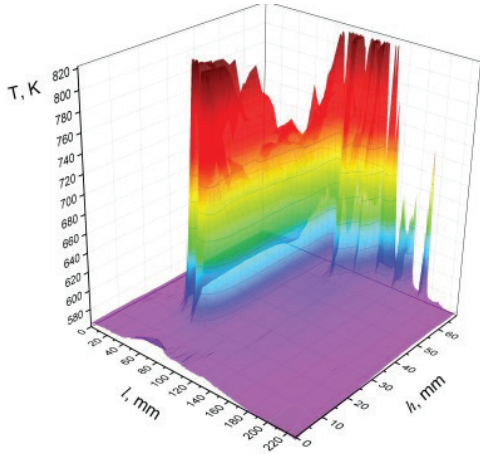

(a)

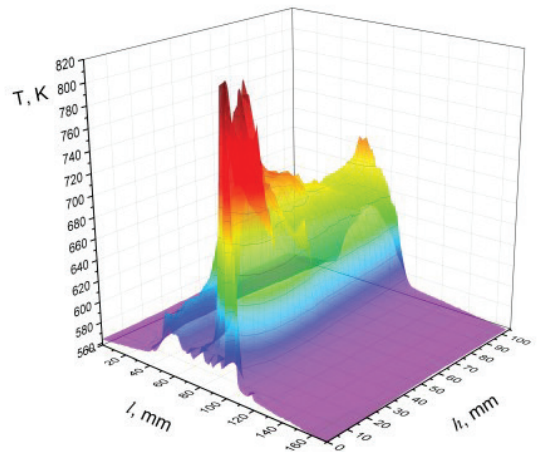

(c)

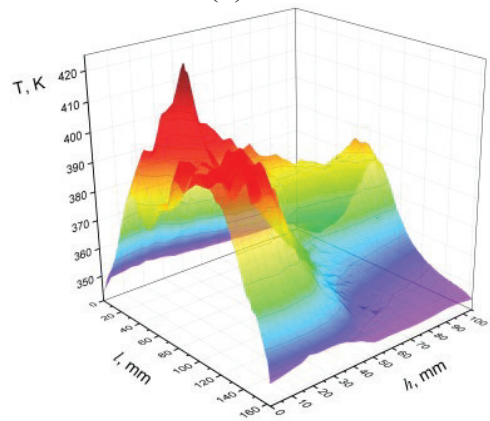

(e)
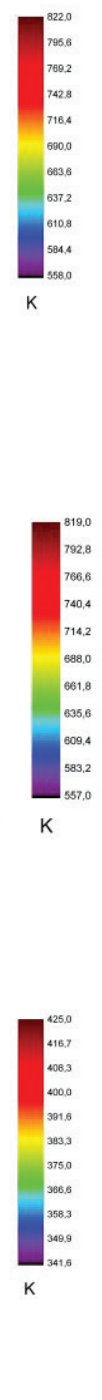

Fig. 2. Surface temperature distribution for the sample of pine ((a) no treatment; (b) treatment with «FUKAM»), aspen ((c) no treatment; (d) treatment with «FUKAM»), and larch ((e) no treatment; (f) with treatment «FUKAM»).

The series of laboratory experiments conducted to investigate the effect of the combustion front initiated by FF showed that charring of the surface was observed for all the wood samples, both with the use of a fire retardant and without it (Fig. 3). However, the 
further combustion process was not observed for the pine and aspen samples treated with a fire retardant. The fire front had no effect on the samples of larch in both cases.
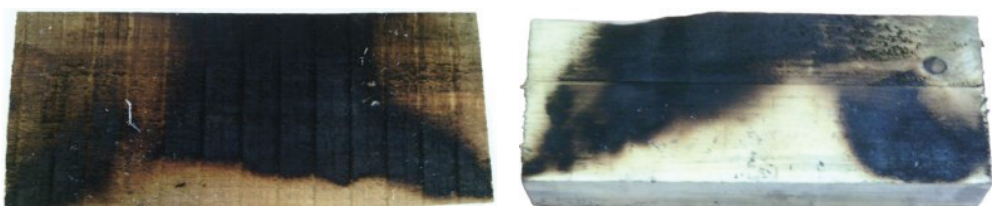

(a)


(b)
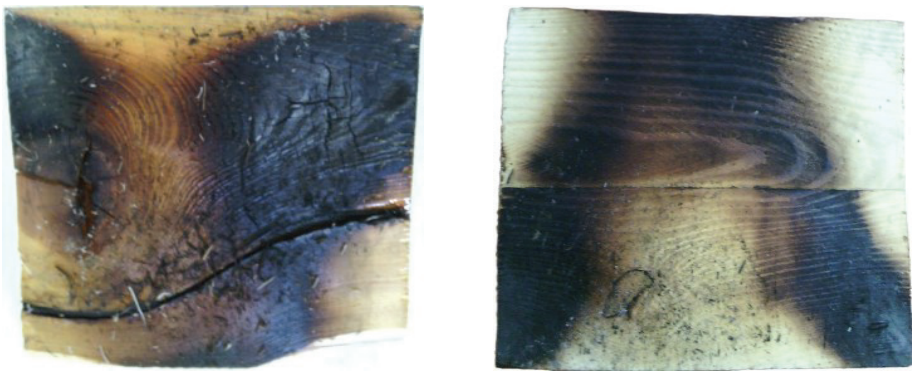

(c)

Fig.3. Wood samples after exposure to the combustion front: (a) pine, (b) aspen, (c) larch (left - no treatment, right - with the fire retardant treatment).

The maximum temperature that was reached on the surface of the samples without a coating was: $820 \mathrm{~K}$ for pine, $800 \mathrm{~K}$ for aspen, and $410 \mathrm{~K}$ for larch and with a coating was $456 \mathrm{~K}$ for pine, $506 \mathrm{~K}$ for aspen, and $471 \mathrm{~K}$ for larch. The nonuniformly laid FF layer was likely to influence on the difference in the temperature values for the larch samples. Fireretardant treatment «FUKAM» could also influence on the sample heating.

\section{Conclusion}

For the chosen experimental parameters the surface of the wood samples became charred, but flame combustion was observed only in a few cases, which appears to be connected to the small capacity of the heat flow, as well as the short duration of its effect on wood, which is confirmed, in particular, by the work [16] that analyzes the experimental characteristics of ignition and combustion of wood subjected to the different thermal flows. As a result, it is concluded that the lower the intensity of the heat flow is, the more 
complete pyrolysis occur at a rate that is low to create a combustible concentration. In addition, as is known, for stable combustion the solid material should obtain the amount of heat that provides a continuous supply of the sufficient amount of gaseous combustible substances in the combustion zone [17].

The use of fire retardant treatment (for example a fire retardant «FUKAM») certainly increases the resistance of wood to fire, which is confirmed by the data on the sample surface temperature after exposure to model combustion.

This study was supported by the Russian Foundation for Basic Research (project No. 16-38-00190) and Tomsk State University, the Fund Program of Academic D.I. Mendeleev, 2016 (grant No. 8.1.27.2016).

\section{References}

1. A. M. Grishin, A. S. Yakimov, Thermophys. Aeromech. 20, 463 (2013).

2. W.E. Mell, S.L. Manzello, A. Maranghides, D. Butry, R.G. Rehm, Int. J. Wild. Fire 19, 238 (2010).

3. J. D. Cohen, J. Forest. 98, 3 (2000).

4. V.T. Kuznetsov, A.I. Fil'kov, Combust. Explos. Shock Waves 47, 65 (2011).

5. A.M. Grishin, A.I. Fil'kov, J. Eng. Phys. Thermophy. 76, 1139 (2003).

6. A.M. Grishin, A.I. Filkov // Fire Saf. J. 46, 56 (2011).

7. J.-L. Rossi, K. Chetehouna, A. Collin, B. Moretti, J.-H. Balbi, Combust. Sci. Technol. 182, 1457 (2010).

8. V. Babrauskas, Fire Saf. J. 40, 528 (2005).

9. S. D. Tse, A. C. Fernandez-Pello, Fire Saf. J. 30, 333 (1998).

10. J. D. Cohen, USDA Forest Service Gen.Tech.Rep. PSW-GTR 173, 189 (2000).

11. S. L. Manzello, S. Suzuki, Y. Hayashi, Fire Saf. J. 54, 181 (2012).

12. R. Sh. Enaleev, I. V. Krasina, V. S. Gasilov, Yu. S. Chistov, O. A. Tuchkova,Vestnik Kazanskogo tehnologicheskogo universiteta 10, 99 (2013).

13. L. Lowden, T. Hull, Fire Sci. Rev. 2, 4 (2013).

14. The special substance for processing different fabrics and building materials «FUKAM»: http://www.fukam.ru/English/

15. V. P. Vavilov, Thermal/Infrared Nondestructive Testing.-NDT Handbooks series (Spectrum, Moscow, 2009).

16. I. M. Abduragimov, A. S. Androsov, M. Bartak, Combust. Explos. Shock Waves. 22: 7 (1986).

17. A. Ya. Korolchenko, Protsessyi goreniya i vzryiv (Pozhnauka, Moscow, 2007). 